\title{
Assess the Knowledge of Staff Nurses Regarding Alzheimer's Disease in Government General Hospital Guntur
}

\author{
K.Suganthi M.sc (N) R.N, R.M
}

\begin{abstract}
A descriptive study was conducted "To assess the knowledge of staff nurses regarding Alzheimer' disease in Govt General hospital Guntur. A.P. India. The objectives are 1.To assess the knowledge of staff nurses regarding Alzheimer's disease. 2. To associate the knowledge levels with selected demographic variables like age, education and experience. The sample were selected by using purposive sampling by use self administered questionnaire. The finding of the study reveals that $24 \%$ of nurses have above average knowledge, $60 \%$ nurses have average knowledge and $26 \%$ of nurses have below average knowledge
\end{abstract}

\section{Introduction}

Good health is a pre-requisite of human productive and development process and is essential to economic and technological development. Health or wellness is not merely the absence of illness as per the World Health Organisation "Health is a state of complete physical mental and social well being not merely the absence of disease or infirmity". There is no health with out mental health. A state of well being, in which every individual realizes his or her own potential.

When William Shakespeare, describing the stage of human existence, wrote "Sans teeth, Sans eyes, Sans taste, Sans everything........." (In As you like it). He probably had as his muse an elderly person with Dementia. Progressive los of brain and mind functions occur in many elders with memory for recent events coexisting with aberrant behaviour patterns. Other brain functions such as language, praxis (the ability to perform complex motor tasks like brushing ones teeth); and arithmetic ability are impaired, as also social judgment, insight (awareness of one's condition) and personality. Indeed, so affected is the human condition that Dementia has been described as a "fate worse than death". Dementia is clearly linked with aging; that is, the longer one lives the more likely one is to develop it.

Contrary to what many would believe, Dementia is not actually a regular part of aging. Dementia is actually caused by disease or as the result of physical damage to the body. Severe memory loss is never a normal part of growing older. Rather, the symptoms are due to brain diseases, which seem to be more common in older people.

4* The term "dementia" refers to a range of symptoms commonly found in people with brain disease which result in the damage and loss of brain cells. Losing brain cell is a natural process, but with illness leading to Dementia this occur at a much faster rate and result in the person's brain not functioning in a normal manner.

\section{Need for the study}

Dementia describes a loss of mental function, usually associated with old age, involving problems with memory and reasoning. Dementia is a loss of mental abilities so serve it interferes with a person's ability to function normally at work or in social settings. It is characterized by impairment of short and long term memory and disintegration of personality due to impaired insight and judgment. Dementia is a major public health problem, with a severe impact on millions of affected people and their families. (Bimla kapoor)

Brain cells in the cerebral cortex, hippocampus, which is responsible for intellectual activities like memory and reasoning. This interfere with the intricate process of cell-to-cell communication in the brain. This disease was first described in 1907 by the physician Alois Alzheimer symptoms usually occur before the age of 60 years and progress rapidly, the probability of developed Alzheimer' disease increases with advancing age. It occurs primary Middle or late in life.

$1 *$ The World Health Organizations, International classification of diseases describes Dementia in the clinical descriptions and diagnostic guidelines as : a Syndrome due to disease of the brain, usually of a chronic or progressive nature in which there is disturbance of multiple higher cortical functions including memory, thinking, orientation, comprehension, calculation, learning capacity, language and judgment. Impairment of cognitive function are commonly accompanied, and occasionally preceded, by deterioration in emotional control, social behaviour or motivation. This syndrome occur in Alzheimer's disease, and in other conditions primarily or secondarily affecting the brain. 
Alzheimer's disease is a form of dementia, complex brain disorder caused by a combination of various factors. These factors may include genes, neuro transmitter changes, vascular abnormalities, stress hormones, circadian changes, head trauma and seizure.

The most common form of Dementia is Alzheimer's disease followed by Vascular Dementia and Mixed Dementia (a condition with featured of both Alzheimer's disease and Vascular Dementia). Rarer forms of Dementia include Dementia with Lewy bodies, Dementia in Parkinson's disease, extreme alcohol abuse, AIDS Dementia Complex, Huntington's disease, Creutzfeldt Jakob disease and Pick's disease.

$3 *$ The symptoms of Dementia are not the result of old age. Severe memory loss is never a normal part of growing older. Rather, the symptoms are due to brain diseases, which seem to be more common in older people. Dementia symptoms may be static or progressive depending on the underlying disease, and how it is treated. Static Dementia usually follows a single major injury like a severe head trauma or heart attack. It does not progress in severity, but remains stable. Progressive Dementia, however, does become worse over time. This type of Dementia is found in several major brain disorders.

Whether it occur suddenly or gradually, Dementia causes many disabling symptoms, including :-

- $\quad$ Memory disturbance

- $\quad$ Personality change

- Impairment of judgment and control of impulses

- Confusion or disorientation

- Diminishing initiative

- Deterioration of intellectual capacity

- Depression, anxiety

- $\quad$ Obsessive behaviour

The key feature is the decline in intellectual functioning, which significantly interferes with normal social relationships and daily activities.

Aging is a natural process which extended during the course of life, starting from conception then gradually birth of the baby, infancy, childhood, adulthood their old age and ultimately leading to the death of the human beings.

Dementia is an incurable disease of the brain that causes progressive deterioration in thinking, memory and every day abilities. Dementia is not a normal part of aging and has been recognized as the cause of disability in five to ten percent of the world's population. Morbidity indicates that dementia is by far the most important single contributor to neurological and sense disorder burden.

There are over 24 million people with Dementia worldwide with 6 million new cases every year that is one new case every seven seconds. The number of people affected is expected to double every 20 years (it will be 811 million by 2040) with 71 percent of them living in developing countries.

The geriatrics population is more than younger population. In India where one-third of the aged population of the world live, will see a phenomenal increase in the above 60years age group has been projected by WHO for the year 2025 - 2050 the 75 percent of the world load of elderly population. Nurses mainly community oriented nurses need to educate or refer the population in order to prevent or control the dementia. $5^{*}$

Today an essential five million Americans and their families suffer the deviation of Alzheimer's diseases. By 2050, that number is expected to climb as high as 16 million, unless something is done to delay or prevent the onset of the disease.

- 35.6 million people worldwide have Alzheimer's disease and other dementia's incidence projected to double even 20years.

- Total economic burden of 315 million with increaser driven from law and middle income countries

$6^{*}$ Growth in dementia over the next 20 year will be much steeper in law and middle compared with high income countries. The report fire casts a $40 \%$ increase in numbers in Europe 63\% in North America, $77 \%$ in this Southern Latin America cone and $89 \%$ in the developed Asia Pacific countries.

The nurse who is working in hospital set up need to have broader understanding of Alzheimer's disease and their treatment approach. Nursing care for patients of Alzheimer's disease is most important, whether at home in an acute hospital environment, a day-care centre or in a long term stay institution. Care givers must be trained to promote the patient's remaining intellectual abilities, help them maintain their independence in attending to their daily functions and avoid injuries and provide for good quality of life.

\section{Statement of the problem}

"Assess the knowledge of staff nurses regarding Alzheimer's disease”. In Govt. General Hospital, Guntur Objective of the study:

- $\quad$ To assess the knowledge of staff nurse regarding Alzheimer's disease.

- $\quad$ To determine the association between knowledge and selected demographic variables.

Operational definition: 
Assess: Statistical measurement of the knowledge of staff nurse regarding Alzheimer's disease by their responses from questionnaires.

Knowledge: The score obtained by the staff nurse regarding Alzheimer's disease questionnaires.

Staff nurse: A person who is qualified professionally GNM or B.Sc. Nursing, or M.Sc Nursing and working in the hospital.

Alzheimer's disease: Alzheimer's disease is a progressive, irreversible, degenerative neurologic disease that begins insidiously and is characterized by gradual loss of memory.

Limitation: The study is delimited to

- $\quad$ staff nurses in GGH, Guntur.

- Staff nurses who are willing to participate in the study.

Hypothesis:

- $\quad$ There will be significant association between knowledge of staff nurses and selected demographic variables.

\section{Materials and Methods:}

The research approach used in the study was descriptive study / non experimental study. The research design selected for the study was descriptive method.

\section{Setting of the study :}

The study was conducted in Governmental General hospital, in Guntur

Population: The population for the present study is the staff nurses who are working in the GGH Guntur hospital during data collection

Sampling: The sample size was 50 .

Convenient sampling is used for data collection and Criteria for sample collection are: 1) Staff nurse who are willing to participate in the study. 2) Staff nurse who are on duty/ available during data collection. 3) Staff nurse who can understand and communicate in English.

\section{Data collection tool:}

The knowledge of staff nurse regarding Alzheimer's disease was assessed by use of self administered structured Questionnaires.

The research tool was developed by doing extensive literature reviews. Experts from various yields like medical surgical and mental health have given this valuable opinion and valuable suggestion to develop the research tool. The data collection tool consists of two sections.

Section A: Demographic Data. It consists of demographic data such as age, education, religion, community and experience.

Section B: Questionnaire to assess the knowledge of staff nurse regarding Alzheimer's disease. It consists of 40 items regarding knowledge of staff nurse regarding Alzheimer's disease.

Each item has 4 options with most appropriate answer. The maximum score for correct responses to each score in one. Therefore 40 items, there was 40 maximum obtainable score.

Reliability of tool was tested by test - retest method and it was found to be reliable [ $\mathrm{r}=0.96$ ]

In order to collect the data for the study the investigator obtained written permission from medical superintendent, Govt. General Hospital, Guntur. The study was started from $16^{\text {th }}$ July, 2010 to $25^{\text {th }}$ July, 2010. The questionnaire was given to staff nurse and collected after one hour at their different duty schedule.

After collecting the data, it was planned to analyse the same by using descriptive type and inferential statistics i.e., mean, standard deviation and chi square. The analysis and interpretation of data was planned in 3 parts.

Section I: Formulating frequency and percentage distribution of demographic data of staff nurses selected for the study.

Section II: Assessing the knowledge of staff nurses by using questionnaires.

Section III: Associate the knowledge of staff nurse with demographic variable.

\section{Results}

Frequency and percentage distribution of staff nurse according to Demographic variables $\mathbf{N}=50$

\begin{tabular}{|c|c|c|}
\hline AGE & FREQUENCY & PERCENTAGE \\
\hline $21-30$ & 09 & 30 \\
\hline $31-40$ & 15 & 36 \\
\hline $41-50$ & 18 & 16 \\
\hline$>50$ & 08 & 100 \\
\hline Total & 50 & 56 \\
\hline EDUCATION & & 28 \\
\hline
\end{tabular}


Assess the Knowledge of Staff Nurses Regarding Alzheimer's Disease in Government ....

\begin{tabular}{|c|c|c|}
\hline B.sc(N) & 20 & 40 \\
\hline M.sc(N) & 02 & 04 \\
\hline Total & 50 & 28 \\
\hline WORK EXPERINECE & & 44 \\
\hline $01-8$ years & 14 & 12 \\
\hline $09-16$ years. & 22 & 16 \\
\hline $17-24$ years & 06 & 100 \\
\hline$>24$ years & 08 & 60 \\
\hline Total & 50 & 100 \\
\hline RELIGION & & 40 \\
\hline Hindu & 15 & 100 \\
\hline Christian & 25 & 120 \\
\hline Muslim & 10 & 80 \\
\hline Total & 50 & 100 \\
\hline COMMUITY & & \\
\hline Urban & 30 & \\
\hline Total & 20 & \\
\hline
\end{tabular}

Frequency and Percentage Distribution of level of knowledge of staff nurse regarding Alzheimer's disease $\mathbf{N}=\mathbf{5 0}$

\begin{tabular}{|c|c|c|}
\hline KNOWLEDGE LEVEL & FREQUENCY & PERCENTAGE \\
\hline Above average( $>51 \%)$ & 13 & 26 \\
\hline Average $(36-50 \%)$ & 30 & 60 \\
\hline Below average $(<35 \%)$ & 07 & 14 \\
\hline
\end{tabular}

Association between the level of knowledge of staff nurses regarding Alzheimer's disease and their selected demographic variable $\mathrm{N}=\mathbf{5 0}$

\begin{tabular}{|l|c|c|}
\hline DEMOGRAPHIC CHARACTERSTICS & CHI SQUARE & df \\
\hline 1. Age & 0.04 & 06 \\
\hline 2. Education & .04 & 04 \\
\hline 3. Work experience & 0.01 & 04 \\
\hline 4. Community & 4.15 & 06 \\
\hline 5.Religion & 3.979 & 04 \\
\hline
\end{tabular}

To assess the knowledge of staff nurse regarding Alzheimer's disease. From the analysis it was found that the knowledge level of staff nurses regarding Alzheimer's disease as follows: regarding Introduction (84.4\%); causes (93.7); signs and symptoms (88.1\%); diagnostic findings (78\%); and complication $(40 \%)$

Demographic variable such as age, education, work experience Chi square values i.e.0.04,0.04 and 0.01 were significant at $p<0.05$ level. It revealed there is significant association between knowledge of staff nurse and their age, education, work experience. Where as religion and community Chi square values i.e. were in significant at $\mathrm{p}<0.05$ level.

\section{Conclusion}

Alzheimer's disease is the most common form of dementia in older people. People with Alzheimer's disease may have trouble in remembering things that happened recently or unable to remember the name of the people they know. Nurses are the person who closely move with patient and public, so the nurses are able to identify the memory problems of the patient in geriatric medicine .Geriatric nursing also get importance today due to increasing population of aged. Nurses have an important role in providing elderly care and educate the family member. They are also centre person to play an acknowledgement and supporting the care provided by family and friends to individual with Alzheimer's disease.

\section{References:}

[1]. Brunner and suddarth, "Text book of surgical nursing" $11^{\text {th }}$ edition, Lippincott publication , 2009, page no $243-244$.

[2]. Niraj Ahuja, "Text book of psychiatric nursing", $6^{\text {th }}$ edition, Jaypee publication ,2006, page no24-29.

[3]. Dr.Bimla Kapoor, "Text book of psychiatric nursing”, $1^{\text {st }}$ edition ,Kumar publishing house,2006,pge no 139.

[4]. Lewis, "Text book of medical surgical nursing", $5^{\text {th }}$ edition Moby Inc publication 2000,page no 1702-1708.

[5]. Inter national journal, Geriatric psychiatry, vol. 15, pg no. 393-400

[6]. Nightingale nursing time, vol.1 issue 12, 2006, pg no. 50-54 